\title{
Comparison between the draf Ilc and standard draf Ilb procedure for frontal sinus drainage: single center experience and comparison of outcomes
}

\begin{abstract}
Aims: Inadequate surgical frontal sinus drainage in chronic sinusitis cases refractory to conservative treatment results in a poor clinical response and is associated with recurrent frontal recess stenosis. Endonasal frontal sinus drainage procedures are classified according to Draf into three groups: DrafIIb enables unilateral orbit to septum drainage and the IIc is the extension of the IIb across the midline. The purpose of our report is to review chronic sinusitis cases treated at our Department using the standard (IIb) or modified (IIc) procedure and compare results.
\end{abstract}

Methods: Patient- and surgery-related data were retrieved on patients operated between 2013 and 2016 for chronic frontal sinusitis using the standard/modified DrafIIb procedure. The modified IIb (i.e. IIc) procedure was performed so that both frontal sinus ostia were visualized by performing an intersinusseptectomy: the aim was to provide drainage to both frontal sinuses simultaneously.

Results: In the observed period, 26 patients were treated: 12 using the modified DrafIIb (IIc) and 14 using the standard DrafIIb procedure. There were no significant differences between groups regarding age, sex, number of previous procedures or follow-up period. All patients had an uneventful postoperative recovery and there were no cases of re-stenosis observed in the DrafIIc group; there were seven cases of restenosis in the DrafIIb group.

Conclusion: The extension of the DrafIIb across the midline (IIc) offers good results and should be considered as an addition to standard care for selected chronic frontal sinusitis cases.

Keywords: chronic rhinosinusitis, drafprocedure, frontal sinus drainage, frontal intersinus septum, intersinusseptectomy
Volume I2 Issue 5 - 2020

\author{
Aigerim Kvarantan,' Gorazd Poje, ${ }^{2}$ Livije \\ Kalogjera ${ }^{3}$ \\ 'Department of Otorhinolaryngology, County Hospital Čakovec, \\ Croatia \\ 2Department of Otorhinolaryngology, Head and Neck Surgery, \\ University Hospital Center Zagreb, Croatia \\ ${ }^{3}$ Department of Otorhinolaryngology, Head and Neck Surgery, \\ University Hospital "Sestre Milosrdnice", Croatia
}

\begin{abstract}
Correspondence: Aigerim Kvarantan, County hospital Čakovec, ul. Gorana Kovacica IE, Čakovec, Croatia
\end{abstract}

Tel +385 (0)-955574370, Email a.zhumabayeva@gmail.com

Received: December 03, 2020 | Published: December II,

2020
Abbreviations: EFSS, endoscopic endonasal frontal sinus surgery; lamina papyracea, orbital plate of the ethmoid bone; CT, computerized tomography; P, classic nasal polypectomy; En, endonasal endoscopic approach; Ex, external approach (osteoplastic flap procedure); C, combined endonasal endoscopic and external approach

\section{Introduction}

In spite of the ever-advancing technological aids, frontal sinus surgery continues to be among the most challenging aspects of endoscopic sinus surgery, mainly due to a difficult visualization of a variable anatomy, and close proximity to the orbital plate of the ethmoid bone (lamina papyracea) and the anterior skull base. Endoscopic endonasal frontal sinus surgery (EFSS) is mostly performed for cases of chronic frontal sinus inflammatory disease which fail to respond to non-surgical treatment. The aim of these procedures is to achieve drainage of the frontal sinuses and thus disrupt the pathophysiological cycle perpetuating the inflammation. The EFSS procedures are graded according to the Draf classification, based on extensivity, into three categories: type I - simple drainage; type II a/b extended drainage; and type III - endonasal median drainage. ${ }^{1}$ Recently, an extension of the Draf IIb drainage was described in which the standard procedure resection of the frontal sinus floor from the orbital plate of the ethmoid bone (lamina papyracea) to the nasal septum - is augmented by an extension across the midline, yet not to the opposite frontal recess. ${ }^{2}$
The procedure is reserved for cases with a specific anatomic setting in which the more extensive resection, the Draf III, is deemed either unnecessary or impossible. ${ }^{2}$ Reports on the Draf IIc procedures have been scarce so far and diverse with regard to patient populations, follow-up length; in general, the reported outcomes have generally been favorable..$^{3-5}$ Our aim is to report on our cohort of patients who underwent the Draf IIc procedure and to compare the results with the standard IIb procedure. Illustrative cases are presented.

\section{Patients/materials and methods}

\section{Study design and setting}

From the institutional digital archive all patients who underwent an endoscopic endonasal frontal sinus surgery - either the Draf IIb procedure, or the Draf IIc procedure - between January 2013 and December 2016 were identified. No exclusion criteria were set with regard to type or number of previous procedures, or with regard to underlying pathology.The following data were retrieved: sex, age, indication for surgery, type of surgery, type and number of previous operations, follow-up, and clinical outcome (i.e. restenosis).

\section{Surgical procedure}

All procedures were performed under general hypotensive anesthesia. Standard $30^{\circ}, 45^{\circ}$, and $70^{\circ}$ rigid endoscopes (Karl Storz GmbH \& Co, Tuttlingen, Germany) were used under 
navigation (Medtronic Fusion EM Navigation) control during the procedure. After identifying the frontal recess without removing the middle turbinate (in some cases the middle turbinate was resected during previous surgeries) frontal sinus ostium is enlarged from the orbital plate of the ethmoid bone (lamina papyracea) to the middle turbinate. Following a navigation control, the contralateral frontal sinus is entered by drilling bone from the lateral margin of the opening toward the inferomedial point of the contralateral frontal sinus so that the inferior portion of the frontal interseptum is exposed (Case 2, figure 9B, 9C). In order to reach the contralateral frontal sinus through the anterior insertion of the middle turbinate a portion of the nasal beak is usually removed. After widening the contralateral frontal sinus ostium and visualizing the interseptum as much as possible, intersinus septectomy is performed. The latter step constitutes the extension of the DrafIIb procedure into DrafIIc, the purpose of which is to enable a wide communication with the contralateral frontal sinus. The schematic view of bone removal is shown in Figure 1.

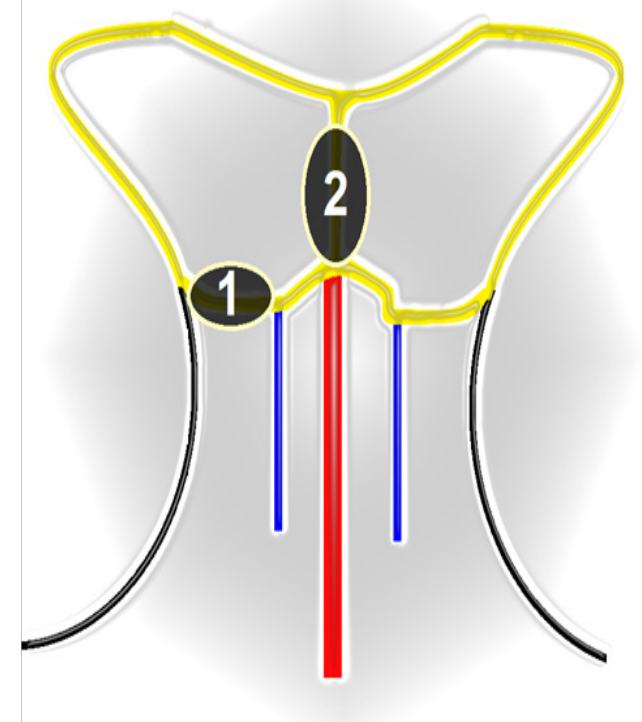

Figure I Schematic view of the procedure. (I) bone between the orbital plate of the ethmoid bone (lamina papyracea) and the middle turbinate is removed followed by; (2) removal of the intersinus septum. Image courtesy of GorazdPoje, MD.

\section{Statistical analysis}

Categorical variables were summarized as absolute (relative) frequencies and continuous variables as median (range). Medians were compared using the Mann-Whitney U-test and proportions using the chi-square test. Statistical significance was set at $\mathrm{P}<0.05$.

\section{Illustrative cases}

\section{Case I}

A 56-year-old Caucasian male was operated at our Department for recurrent frontal recess obstruction using the Draf IIc procedure. Previously he had been operated three times for chronic rhinosinusitis with nasal polyposis: in 1981 a classic nasal polypectomy (no medical history); in 1999 endoscopic endo nasal polypectomy (no medical history); and in 2011 Draf IIb procedure bilaterally. The patient was successfully operated at our Department using the Draf IIc procedure, recovered uneventfully, and remains clinically stable at 39 months follow-up. Clinical and intraoperative findings are shown in Figure 2.

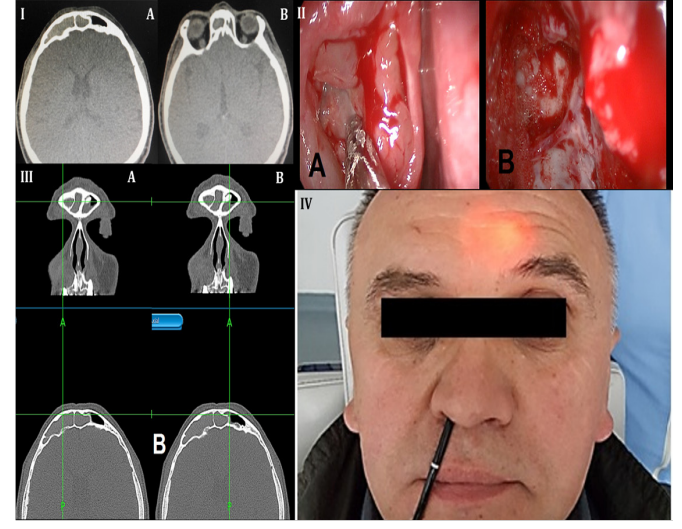

Figure 2 Clinical and intraoperative findings of the patient case \#I. CT scan two years after the first surgery. (I) the right frontal sinus and the frontal recess is completely blocked by inflammatory tissue: (A) polypous tissue from right ostiomeatal complex; (B) signs of ethmoidectomy. (II) the right frontal sinus is opened - the aspirator is pointed toward the point for drilling toward the opposite sinus: (A) drilling toward the intersinus septum; (B) the left frontal sinus can be seen after the intersinus septum is removed (both frontal sinuses communicate). (III) navigation probe in the right (A) and left frontal sinus (B). (IV) contralateral frontal sinus endoscopy is be performed by a flexible endoscope through the right frontal sinus extended ostium. Illumination of the left frontal sinus through the anterior wall.

\section{Case 2}

A 60-year old Caucasian female with recurrent frontal recess obstruction was operated at our Department in 2014 using the Draf IIc procedure. Previously she underwent two procedures: in 2009 an endoscopic endonasal surgery and osteoplastic flap procedure due to a frontal sinus osteoma and in 2011 a Draf IIa procedure to treat a right frontal recess reclosure with a clinical manifestation of frontal sinus obstruction. The procedure performed at our Department was complication-free, the patient recovered well and remains clinically stable at five years follow-up. Clinical and intraoperative findings are shown in Figure 3.

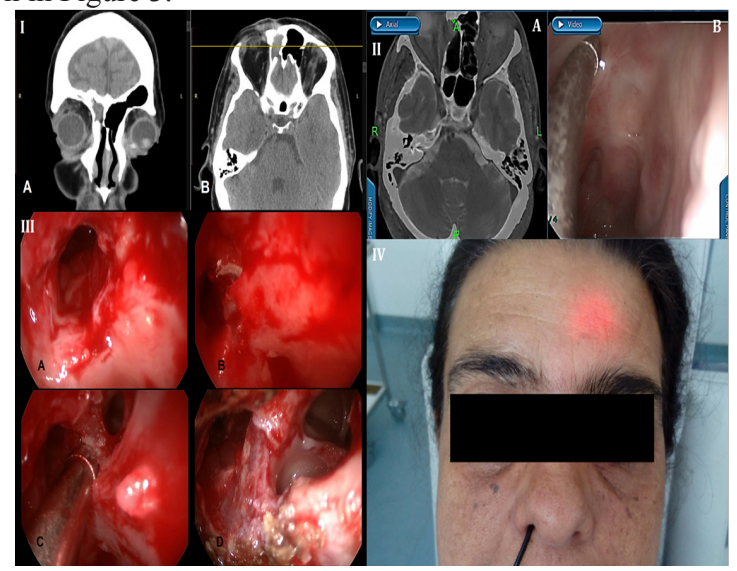

Figure 3 Clinical and intraoperative findings of the patient case \#2. (I) preoperative coronal (A) and axial (B) CT scan of the paranasal sinuses. Obstructed right frontal sinus. Interruption of bone continuity of the anterior and posterior lamina can be seen. (II) Intraoperative (A) navigation and $(B)$ video showing a complete obstruction of the right frontal recess. (III) intraoperative image: (A) beginning of drilling toward the left fontal side; (B) the left frontal sinus ostium is extended using the angled drill and communication with left frontal sinus is established; (C) instrument pointing toward the intersinus septum; (D) widened communication with the left frontal sinus. (IV) postoperative clinical finding - transillumination of left frontal sinus via the right frontal recess. 


\section{Results}

In the observed period, 26 patients were treated for frontal obstruction using a purely endoscopic approach: 12 patients underwent the Draf IIc procedure and 14 patients underwent the standard Draf IIb procedure. Overall, median age at surgery was 43.5 years (range, 2667 years), in the Draf IIc group was 46.5 years (range, 31-67 years), in the Draf IIb group 37 years (range, 26-65 years); the difference was not statistically significant $(\mathrm{P}=0.246)$. Male/female ratio was $14: 12$ (53.8/46.2); in the Draf IIc group 7:5 (58.3/41.7\%); in the Draf IIb group 7:7 (50/50\%); the difference was not statistically significant $(\mathrm{P}=0.713)$. In the Draf IIc group, nine patients $(75 \%)$ had previously undergone a sinus surgery; one of the patients had three previous procedures $>$; two patients had two previous procedures (combined and endonasal endoscopic); six patients had one previous procedures - three of them were treated via an endonasal endoscopic, two via an external, and one via a combined approach. In the Draf IIb group $13(92.9 \%)$ had previously undergone a sinus surgery; two patients had two previous procedures and 11 patients had a single procedure. The difference between groups in the proportion of previously operated patients was not significant $(\mathrm{P}=0.306)$. The groups differed significantly in re-stenosis rates ( 0 patients in the Draf IIc group vs. 7 in the Draf IIb group). Patient data are summarized in (Tables $1 \& 2$ ).

Table I Summary of patient data who underwent the Drafllc procedure

\begin{tabular}{lllllll}
\hline \multirow{2}{*}{ Patient no. } & Sex & Age & Initial diagnosis & \multicolumn{2}{l}{ Previous surgery } & Follow up (months) \\
\cline { 5 - 6 } & & & & no. & type & \\
\hline I & M & 56 & Chronic rhinosinusitis with nasal polyps & 3 & P, C, En & 39 \\
3 & F & 60 & Osteoma of ethmoid sinus & 2 & C, En & 54 \\
4 & M & 46 & Osteoma of sphenoethmoid recess & 0 & - & 27 \\
5 & F & 32 & Mucocele of frontal sinus & 0 & - & 33 \\
6 & M & 31 & Inverted papilloma & I & En & 37 \\
7 & F & 56 & Chronic rhinosinusitis with nasal polyps & I & En & 36 \\
8 & M & 39 & Allergic fungal rhinosinusitis & 0 & C & 34 \\
9 & M & 53 & Chronic rhinosinusitis with nasal polyps & I & Ex & 33 \\
I0 & F & 40 & Mucocele of ethmoid sinus & 2 & C, En & 29 \\
II & M & 51 & Chronic rhinosinusitis with nasal polyps & I & En & 25 \\
I2 & F & 47 & Chronic frontal sinusitis & I & Ex & 22 \\
average & M & 44 & Chronic rhinosinusitis with nasal polyps & I & En & 17 \\
\hline
\end{tabular}

$\mathrm{P}$ - classic nasal polypectomy;

En -endonasal endoscopic approach;

Ex - external approach (osteoplastic flap procedure);

$\mathrm{C}$ - combinedendonasal endoscopic and external approach;

average numbers are medians

Table 2 Data summary of patients who underwent the Drafllb procedure

\begin{tabular}{|c|c|c|c|c|c|c|}
\hline \multirow{2}{*}{ Patient no. } & \multirow{2}{*}{ Sex } & \multirow{2}{*}{ Age } & \multirow{2}{*}{ Initial diagnosis } & \multicolumn{2}{|c|}{ Previous surgery } & \multirow{2}{*}{ Follow up (months) } \\
\hline & & & & no. & type & \\
\hline I & $\mathrm{F}$ & 33 & Chronic rhinosinusitis with nasal polyps & 1 & En & 18 \\
\hline 2 & M & 45 & Chronic rhinosinusitis without nasal polyps & 1 & En & 24 \\
\hline 3 & $\mathrm{~F}$ & 37 & Osteoma of nasofrontal recess & 1 & En & 36 \\
\hline 4 & M & 53 & Chronic rhinosinusitis without nasal polyps & 0 & - & 24 \\
\hline 5 & $\mathrm{~F}$ & 35 & Mycetoma of nasofrontal recess & 2 & Ex, En & 36 \\
\hline 6 & M & 35 & Trauma, mucopyocele of frontal sinus & 1 & Ex & 24 \\
\hline 7 & $\mathrm{~F}$ & 37 & Chronic rhinosinusitis with nasal polyps & 1 & En & 18 \\
\hline 8 & $\mathrm{~F}$ & 47 & Chronic rhinosinusitis without nasal polyps & 1 & En & 24 \\
\hline 9 & M & 34 & Osteomasphenoethmoid recess & 0 & En & 24 \\
\hline 10 & $\mathrm{~F}$ & 43 & Chronic rhinosinusitis without nasal polyps & 1 & En & 18 \\
\hline
\end{tabular}


Table Continued...

\begin{tabular}{|c|c|c|c|c|c|c|}
\hline \multirow{2}{*}{ Patient no. } & \multirow{2}{*}{ Sex } & \multirow{2}{*}{ Age } & \multirow{2}{*}{ Initial diagnosis } & \multicolumn{2}{|c|}{ Previous surgery } & \multirow{2}{*}{ Follow up (months) } \\
\hline & & & & no. & type & \\
\hline 11 & $\mathrm{~F}$ & 35 & Chronic rhinosinusitis with nasal polyps & 2 & En & 36 \\
\hline 12 & M & 26 & Cystic fibrosis & 2 & En & 24 \\
\hline 13 & M & 65 & Trauma, mucopyocele of frontal sinus & 0 & Ex,En & 24 \\
\hline 14 & M & 57 & Chronic rhinosinusitis with nasal polyps & 1 & En & 18 \\
\hline average & $7 M / 7 F$ & 37 & & & & 24 \\
\hline
\end{tabular}

En - endonasal endoscopic approach;

Ex - external (osteoplastic flap procedure) approach;

average numbers are medians

\section{Discussion}

Results of recent studies show relatively high and comparable rates of mucosal hyperplasia in ventilated frontal sinuses of patients who underwent an endoscopic drainage procedure: after a 12-98 month follow-up $12 \%$ in type II and $17 \%$ in type III procedure..$^{6-8}$ Hyperplastic mucosa after an endoscopic rhinosurgery does not necessarily dictate an adjunctive conservative therapy, in particular not when these patients are symptom-free and have a normal endoscopic finding, in spite of a thickened mucosa seen on a computerized tomography (CT) scan. In our experience, CT and endoscopic findings often do not correlate well when the former shows mucosal thickening. Endoscopic follow-up in such cases are of prime importance since it offers a direct view into the local status of the frontal sinus, whereas CT scanning is both harmful and shows the status of the mucosa only indirectly. In addition to being less harmful, endoscopic follow-up is more available and less expensive than the imaging method.All patients in our cohort were followed-up endoscopically.

By using the Draf IIc technique, in addition to providing sufficient long-term ventilation of both frontal sinuses, we were able to open a corridor which enables simultaneous endoscopic follow up of bilateral frontal sinus drainage. Technological aids have proven to be indispensable in the described technique, i.e. widening of the frontal ostium through the midline contralaterally - a $45^{\circ}$ and $70^{\circ}$ angled drill and optical apparatus and navigation - as they enable manipulation in an anatomically complex space and thus reduce the possibility of orbital and cranial complications.

We followed the patients postoperatively in a periodical mannermonthly for the first three months, then after a three month period, then after six months, and finally annual visits were scheduled. In our 1754 month follow-up period, none of the Draf IIc patients developed a frontal sinus re-stenosis. On the other hand, seven patients in the Draf IIb group developed a nasofrontal recess restenosis after a median of 24 months follow-up.

\section{Conclusion}

Our results indicate that the Draf IIc procedure might be superior to the standard procedure in selected cases, as it reduces the frontal recess obstruction rate, probably owing to a simultaneous drainage pathway for both frontal sinuses through a single widened frontal ostium. There were no complications associated with the procedure and no cases of sinus obstruction recurrence in the follow-up. Having this in mind, we believe that the technique can be considered an alternative even to the more extensive surgical procedures. Endoscopic follow-up is a necessary adjunct to the procedure as it ensures an optimal view of the local status, and is easily available and safe.

\section{Acknowledgments}

None.

\section{Conflicts of interest}

The author declares that there is no conflict of interest to disclose.

\section{Funding}

None.

\section{References}

1. Schick B, Draf W. The frontal sinus. In Rhinology and Facial Plastic Surgery. Stucker FJ, De Souza C, Kenyon GS, et al. editors. Heidelberg, Germany: Springer Verlag Heidelberg. 2009. p. 567-573

2. Al Komser M, Goldberg A. Unilateral transnasal endoscopic approach to frontal sinuses: Draf IIc. Allergy Rhinol (Providence). 2013;4(2):82-87.

3. Eloy J, Friedel M, Kuperan A, et al. Modified mini-lothrop/extended draf IIB procedure for contralateral frontal sinus disease: a case series. Int Forum Allergy Rhinol. 2012;2(4):321 - 324.

4. Gotlib T, Held-Ziółkowska M, Niemczyk K. Extended Draf IIb Procedures in the Treatment of Frontal Sinus Pathology. Clin Exp Otorhinolaryngol. 2015;8(1):34-38.

5. Eviatar E, Taha A, Gavriel H. The efficacy of extended Draf IIb procedure by partial nasal septectomy: long-term follow up. Eur Arch Otorhinolaryngol. 2017;274(7):279 -2797.

6. Y Ma, T Wang, X Zhang, et al. Efficacy of the Modified Endoscopic Frontal Sinus Surgery for recurrent chronic frontal sinusitis. Indian J Otolaryngol. Head Neck Surg. 2014;66(3):248-253.

7. MK Al Komser, Goldberg AN. Unilateral transnasal endoscopic approach to frontal sinuses: Draf IIc. Allergy Rhinol.2013;4(2):e82 - e87.

8. RK Weber, W Hosemann. Comprehensive review on endonasal endoscopic sinus surgery.GMS Curr Top Otorhinolaryngol Head Neck Surg. 2014;14; Doc08 